ISSN 00156043

\title{
ESTUDIOS
}

\section{Medio siglo de Economía Social de Mercado}

\section{José Sols Lucia, Albert Florensa Giménez y Marta Camprodón Rosanas'}

Palabras clave: economía social de mercado, capitalismo, democracia cristiana, Estado de bienestar, doctrina social de la iglesia, pensamiento social cristiano, Initiative Neue Soziale Marktwirtschaft (Iniciativa para una nueva economía social de mercado).

Key words: social economy in the market, capitalism, Christian democracy, welfare state, social church doctrine, social Christian thought, Initiative Neue Soziale Marktwirtschaft (New Social Marketing).

Mots-clés: économie sociale de marché, capitalisme, démocratie chrétienne, état providence, doctrine sociale de l'Église, pensée socialechrétienne, Initiative Neue Soziale Marktwirtschaft.

\section{Introducción}

La Cátedra de Ética y Pensamiento Cristiano del IQS (Instituto Químico de Sarrià, Universidad Ramon Llull, Barcelona) organizó, en el curso 2007-2008, el ciclo de Conferencias IQS de Justicia Económica sobre el tema "La Economía Social de

\footnotetext{
' Los tres autores son investigadores y profesores de la Facultad de Economía IQS (Instituto Químico de Sarrià, Universidad Ramon Llull, Barcelona), miembros de la Cátedra de Ética y Pensamiento Cristiano del IQS, así como del Laboratorio de Análisis y Crítica Social (LACS) del mismo centro. José Sols es doctor en Teología y licenciado en Historia Contemporánea. Albert Florensa es doctor en Administración y Dirección de Empresas y Licenciado en Filosofía. Marta Camprodón es licenciada en Administración y Dirección de Empresas y actualmente prepara su doctorado; es además Directora de Relaciones Internacionales del IQS.
} 
Mercado". El ciclo fue coorganizado con el CEES ("Centre d'Estudis Econòmics i Socials"), de Barcelona. Las cuatro sesiones supusieron un interesante repaso histórico acerca de este sistema económico que ha marcado la historia de la Europa Occidental desde la segunda guerra mundial y que ha supuesto la superación del antagonismo entre capitalismo y socialismo, tomando lo mejor de cada uno: del capitalismo, la libertad de mercado; del socialismo, el Estado que evita las excesivas desigualdades. En este equilibrio, se intenta superar lo peor de cada uno de estos dos sistemas: la ley de la jungla del capitalismo puro, y el control agobiante del Estado socialista. No obstante, la recién estrenada globalización cuestiona seriamente la validez de este sistema en el siglo XXI, dado que una economía global, sin un Estado global, difícilmente podrá ser Economía Social de Mercado.

Eugenio Recio, profesor honorario de ESADE y miembro del CEES, presentó la estructura ideológica de la Economía Social de Mercado. José Sols, coordinador de la Cátedra de Ética y Pensamiento Cristiano del IQS y profesor de la Facultad de Economía IQS, expuso la influencia del pensamiento social cristiano en la Economía Social de Mercado. Josep Antoni Duran i Lleida, Presidente de Unió Democràtica de Catalunya, Secretario General de la Federación Convergència i Unió, Presidente de la Comisión de Exteriores del Congreso de los Diputados, y ex-Consejero de Gobernación de la Generalitat de Catalunya bajo la Presidencia de Jordi Pujol, expuso cómo se desarrolló la Economía Social de Mercado en Europa y en América Latina. Finalmente, Antoni Castells, Consejero de Economía y Finanzas de la Generalitat de Catalunya y diputado en el Parlamento catalán, reflexionó sobre la necesidad de reforma del Estado del Bienestar en el contexto de la globalización.

Todo ello constituye una interesante síntesis acerca de lo que ha sido este primer medio siglo de Economía Social de Mercado. En este artículo presentaremos las ideas más interesantes que se expusieron en aquel ciclo de Conferencias IQS de Justicia Económica, y en sus respectivos debates, todo ello acompañado de reflexiones nuestras. No citaremos cada vez las ideas tomadas de las conferencias. Adentrémonos ya en esta síntesis.

\section{Estructura ideológica}

La Economía Social de Mercado tuvo una doble fundación histórica: en Estados Unidos, con el New Deal del presidente Franklin D. Roosevelt, inspirado en las teorías del economista británico John M. Keynes; y en Europa, concretamente en Alemania, tras la segunda guerra mundial, como intento de elaboración de un 
sistema nuevo, más justo que los anteriores, capitalismo y socialismo. La diferencia entre estos dos orígenes, en Estados Unidos y en Europa, reside en que allí el sistema se adoptó como medida excepcional para salir de la enorme crisis de los años 30, resultado del "crack" bursátil de 1929, sin ánimo de reinventar un sistema radicalmente nuevo, mientras que aquí, en Europa, particularmente en Alemania, la voluntad era decididamente emprender algo nuevo y duradero. Nos centraremos ahora en Alemania.

Tal como explica el profesor Eugenio Recio, tras la segunda guerra mundial, en Alemania se vio claro que los dos sistemas económicos que había habido hasta la guerra en aquel país habían sido desacertados. Por un lado, el liberalismo extremo de la doctrina del "laissez faire, laissez passer" ("dejad hacer, dejad pasar", libertad total de producción y de comercio), que intentó poner en práctica el canciller von Brüning, y que provocó una enorme inflación y un paro masivo, lo cual facilitó el ascenso de Hitler al poder. Por otro, la desafortunada planificación económica del Nacionalsocialismo, que, aunque menos radical que la de la Unión Soviética, no dejaba de ser muy rigurosa: el Estado sometía sin timidez el mercado aparente a los planes gubernamentales de rearme bélico. Las clases populares del país - auténticas desfavorecidas en cualquiera de estos dos sistemas- se arrojaron, desesperadas, a los brazos del mejor postor, Adolf Hitler.

En la cuna alemana de la Economía Social de Mercado confluyeron diversas paternidades. La denominada Escuela Histórica, con sus destacadas aportaciones a los programas de Política Social de la constituida Asociación para la Política Social (Verein für Sozialpolitik); algunas de las propuestas del ordoliberalismo (concepto que en seguida explicaremos) de la Escuela de Friburgo (Alemania), en los años 20 y 30, que defendían el mercado de la competencia-destacamos a Walter Eucken y a Wilhelm Röpke-; los trabajos de sobresalientes figuras del pensamiento social cristiano, como los jesuitas Oswald von Nell-Breuning y Gustar Gundlach o el dominico Arthur Fridolin Utz, así como también algunos moralistas protestantes. Este pensamiento social cristiano encontró una gran receptividad por parte de los políticos de los dos grandes partidos, la Democracia Cristiana² (CDU) y la Socialdemocracia (SPD).

\footnotetext{
2 En este estudio consideraremos sinónimos los conceptos de "democracia cristiana" y de "socialcristianismo", o, lo que es lo mismo, de "democristianos" y de "socialcristianos". El concepto de socialcristianismo hace referencia a la parte social, más de "izquierdas", de la democracia cristiana, pero no alude a alguna otra dimensión de esta ideología, que podría ser considerada de "derechas". Sabemos que hay otras corrientes, de extrema derecha, que también se hacen llamar "socialcristianos", pero no tienen nada que ver con lo que abordamos en este estudio.
} 
Veamos algunos de los principales nombres y apellidos de los padres fundadores de este sistema.

1. Alfred Müller-Armack, cristiano evangélico, economista y filósofo, es, en sentido estricto, el autor propiamente dicho de la Economía Social de Mercado; porque si Ludwig Erhard, siendo ministro de economía, aportó el concepto político, la fundamentación teórica, en cambio, provino de su secretario de Estado, Müller-Armack. En 1952, este profesor de Ciencias Económicas del Estado se pasó a la política, y fue, hasta 1958, jefe de departamento, y después secretario de Estado en el Ministerio de Economía, cuyo titular era Ludwig Erhard. A pesar de la estrecha vinculación entre ambos, hubo también diferencias entre ellos; Müller-Armack intentaba que la Economía Social de Mercado no se desviara hacia el liberalismo.

2. Ludwig Erhard, doctor en Ciencias Económicas, discípulo de Franz Oppenheimer, comenzó su carrera política en 1945 como ministro de economía del Estado (Land) de Baviera. Dos años después, presidió la comisión que preparó la reforma monetaria de la RFA. El canciller Konrad Adenaver le hizo ministro de economía de la RFA en 1949, cargo que conservó hasta ser elegido, en 1963, canciller federal, en sustitución de Adenauer.

3. Walter Eucken realizó aportaciones clave a la hora de definir el concepto de Economía Social de Mercado. Fue profesor de Erhard en la Universidad de Friburgo y, junto con el profesor de Ciencias Jurídicas Franz Böhm, formuló la base teórica de la Escuela de Friburgo (Alemania), que sigue teniendo vigencia en lo que se refiere al principio de la "ordenación", el "ordo", en las Ciencias Económicas y Sociales, idea según la cual el Estado debía limitar su intervención en los procesos económicos a la defensa de la competencia del mercado. Esta corriente fue denominada "ordoliberalismo", e incluso "neoliberalismo de Friburgo", por el hecho de presentar una nueva concepción del liberalismo, pero no hay que confundirla con el también denominado "neoliberalismo" de la Escuela de Chicago (años 70) y del Consenso de Washington (1990), con el que no tiene nada que ver.

Entremos ahora en la estructura ideológica de la Economía Social de Mercado. El término "Economía Social de Mercado", acuñado en 1946, consistía, en palabras de Alfred Müller-Armack, en vincular el principio de la libertad de mercado con el de la compensación o equilibrio social, ${ }^{3}$ dicho en otras palabras: consistía en vincular, en base a una economía de competencia, la libre iniciativa con un

${ }^{3}$ A. Müller.Armack (1976) Wirtschaftsordnung und Wirtschaftspolitik, Berna-Stuttgart, Haupt, segunda edición, 243. 
progreso social garantizado por los rendimientos de la economía de mercado. ${ }^{4}$ Esto suponía, según otro de sus inspiradores, Wilhelm Röpke, "ir más allá de la oferta y de la demanda", título de uno de sus trabajos, Jenseits von Angebot und Nachfrage, publicado por primera vez en Suiza, en 1958. El concepto de Economía Social de Mercado, tal y como lo han entendido Erhard y Müller-Armack no parte, por tanto, de una autonomía intocable del sector privado en sus actuaciones, sino que presupone, según Egon Tuchtfeldt, una eficaz políica económica, impulsada por el Estado. ${ }^{5}$

De las tres variantes en que el pensamiento ordoliberal, o "neoliberal", de Friburgo ha interpretado la economía de mercado (1/ el puro neoliberalismo, que se suele atribuir a los fundadores de la Escuela; 2/ el neoliberalismo sociológico; y $3 /$ el neoliberalismo de orientación cristiana), la Economía Social de Mercado ha escogido la última, la que corresponde a la visión cristiana del ser humano. Veamos cuáles son los dos principios básicos que la vertebran.

\section{I. Dos principios: libertad individual y sensibilidad social}

En primer lugar, la Economía Social de Mercado está vertebrada por el principio de la libertad del individuo como un valor en sí, expresión de la dignidad y de la autorresponsabilidad de la persona humana. Esta libertad se manifiesta en la iniciativa para emprender con creatividad, en la disponibilidad para el rendimiento (con una notable valoración de la función del trabajo en la sociedad) y en el esfuerzo por organizarse con sus propios medios, sin dependencias infantiles del Estado, para autoprevenir y para superar los riesgos de las distintas etapas del desarrollo vital. En 1958, Erhard resumía el significado de este primer principio con estas palabras: el ideal que proponemos se basa en la fortaleza que permite que cada uno diga 'yo quiero valerme con mis propias fuerzas, quiero soportar por mí mismo el riesgo de la vida, quiero ser el responsable de mi destino'. ${ }^{6}$ Como vemos, el Estado socialista soviético y el Estado nacionalsocialista alemán, obsesivamente intervencionistas, quedan muy

\footnotetext{
${ }^{4}$ lbíd., 245.
}

${ }^{5}$ E. TuChtFeldt (1980) "La Economía Social de Mercado, un experimento de Política de Ordenamiento Económico del siglo XX", Ponencias del Simposio Internacional de ESM, Instituto de Dirección y Organización de Empresas de la Universidad de Alcalá de Henares, Cuaderno 3-4, Madrid, ESIC, 23.

${ }^{6}$ Cit. en H. Tietmeyer (2000) "Eigeninitiative und Unternehmergeist - Wie wir die Soziale Marktwirtschaft ernevern können", conferencia pronunciada en Berlín, en octubre de 2000 (www.hanstietmeyer.de). 
lejos de esta teoría económica.

Y el segundo principio que vertebra la Economía Social de Mercado es la sensibilidad social, esto es, la apertura al otro social, que consiste en la vinculación de la persona con la comunidad (respeto a la dignidad de los demás, fundamento de los mismos derechos que tenemos nosotros a nivel personal) y en la adecuada utilización de todos los bienes naturales. Las diversas y cambiantes situaciones de la vida hacen que, involuntariamente, determinados grupos no puedan valerse por sí mismos, estén en situaciones de precariedad, marginalidad o pobreza, y necesiten de la solidaridad de los demás, no tanto excepcionalmente, sino más bien estructuralmente. El Estado juega un papel importante en esta función solidaria, aunque los ciudadanos no deberían dimitir de su responsabilidad social, esperando que el Estado lo arreglase todo, sino que tendrían que asumir acciones participativas en el marco de asociaciones ciudadanas de diversa índole.

Concretemos más. En lo económico, cuando hablamos de Economía Social de Mercado nos referimos a seis características, que corresponden a las siguientes áreas: a) política de competencia, b) política social, c) política de coyuntura, d) política de crecimiento económico, e) política fiscal y de estructuras, y f) criterio de conformidad con el mercado. Armonizadas, constituyen en su conjunto una unidad de estilo, la Economía Social de Mercado, y forman, según Egon Tuchtfeld, una política económica fundida en un modelo único. ${ }^{7}$ Veamos cuáles son estas seis características:

A) Se respeta el libre mercado de competencia, en el que existe la propiedad privada de los medios de producción. Con ello, se descentralizan la actividad y el poder económico y se estimula la iniciativa empresarial para promover el desarrollo económico. La libertad de acceso a los mercados favorece la autonomía personal en sus múltiples facetas. Para ello se necesita una política pública de defensa de la competencia que facilite la presión continua sobre precios y costes, y se hace necesario fomentar la innovación, impedir el poder sobre el mercado y facilitar la distribución de la renta, acorde con el rendimiento. La libertad de la persona en el ejercicio de la actividad económica se garantiza reconociendo la autonomía de los agentes sociales en la determinación de las condiciones de trabajo y, de un modo especial, en su retribución.

7E. TUCHTFELDT (1978) "Die Soziale Markłwirtschaft-Garanteiner gesunden wirtschaftlichen Entwicklung", en VV.AA.: Der Weg aus der Krise, Munich - Viena, Berichte und Studien der Hans-Seidel-Stiftung. 
B) Se lleva a cabo una adecuada política social. Se requiere la intervención del Estado con una legislación social para aquellos casos en los que el mercado no logre resolver los problemas sociales o económicos. Por ello, el Estado crea una red protectora mediante un adecuado sistema de Seguridad Social, un sistema educativo abierto a todos los ciudadanos, así como una buena legislación laboral. La economía de mercado sólo es estable cuando se combina la eficiencia económica con la cohesión social. La conciliación social, además de una cuestión ética, es también una exigencia para que funcione bien el mercado capitalista. En esta área, el gobierno tiene las mayores responsabilidades: asegurar la equidad, la transparencia y la eficiencia del funcionamiento del sistema, sin excluir la colaboración de los particulares.

C) Una política de coyuntura que compense los desequilibrios inevitables que aparecen en todo mercado libre, como pueden ser las fluctuaciones en el empleo y en la balanza de pagos, evitando sus graves consecuencias económicas y sociales. Se da prioridad a la estabilidad monetaria, garantizada por un banco central independiente, pues los procesos inflacionistas perturban la distribución de la renta y de la riqueza, lo cual perjudica especialmente a los pequeños ahorradores y a los rentistas.

D) Una política de crecimiento económico que implique la creación de las condiciones jurídicas y de las infraestructuras necesarias para un desarrollo sostenible, de manera que se pueda dar una innovación en el aparato productivo. Las políticas fiscales estables en relación a la renta y al gasto son esenciales para el trabajo eficiente de una economía de mercado.

E) Una adecuada política estructural debe ofrecer ayudas a los sectores o regiones en los que el mercado no funcione correctamente por razones naturales, técnicas o de otro tipo. En esta política, se debe estimular la adaptación al mercado, fomentando la movilidad profesional o regional.

F) Resulta imprescindible una armonización coherente de todos los principios, objetivos e instrumentos utilizados en las políticas económicas y sociales. En concreto, las políticas correctivas de los procesos del mercado deben ser respetuosas con la idea misma de mercado. No se trata de reducir el mercado, sino de permitir que funcione adecuadamente. La intervención estatal debe distorsionar lo menos posible los procesos del mercado, que básicamente se reducen a esta idea: el precio de los bienes y servicios se establece por la confrontación de la oferta y la demanda. 


\subsection{La ideología de la Economía Social de Mercado en nuestro contexto} histórico: el Foro "Initiative Neue Soziale Marktwirtschaft" (INSM)

Es curioso cómo partidos políticos de diferentes ideologías (de izquierda, de centro y de derecha, nacionalistas y filojacobinos) han hecho suya la Economía Social de Mercado. Prueba de ello es el ciclo de conferencias celebrado en el IQS, y que exponemos aquí de manera sintética, donde intervinieron Josep Antoni Duran Lleida, conocido líder socialcristiano, y Antoni Castells, político socialista, consejero de economía y finanzas del gobierno catalán. No obstante, como veremos enseguida, a la Economía Social de Mercado no se le han ahorrado las críticas, especialmente desde las filas del neoliberalismo gestado en Chicago.

Hans Tietmeyer, economista alemán, que fue Secretario de Estado en el Ministerio Federal de Finanzas y Presidente del Banco Central de Alemania, seguidor de Ludwig Erhard, discípulo de Alfred Müller-Armack, fundó en el año 2000 un foro formado por ciudadanos de diverso origen profesional, sin adscripción a un determinado partido político, que se propone como objetivo renovar el sistema económico y social de Alemania en base a los principios fundamentales de Ludwig Erhard. Este foro se denominó "Initiative Neve Soziale Marktwirtschaft" (INSM), que significa "Iniciativa [para una] Nueva Economía Social de Mercado". Según Tietmeyer, la Economía Social de Mercado no está superada ni están invalidados sus principios fundamentales. Lo que interesa es saber cómo se han de aplicar para que den respuesta adecuada a los problemas de hoy. Erhard ofreció los fundamentos económicos y éticos de una sociedad libre y abierta con el mayor grado posible de iniciativa y responsabilidad propia. La libre competencia propia del mercado debía articularse con el equilibrio social de todos los ciudadanos, para lo cual hacía falta, según Müller-Armack, la intervención estatal. El Estado debía garantizar que el sistema económico estuviera al servicio de todos, pero no debía convertirse en una especie de Estado paternalista, ${ }^{8}$ infantilizante, sino en un Estado del Bienestar que fomentara la responsabilidad personal y la iniciativa privada. En este modelo, el Estado provee de ayuda para los que están necesitados por encontrarse escasamente capacitados para el rendimiento, como puede ser el caso de ancianos, enfermos, impedidos, y colabora en la previsión de riesgos en la vida humana.

\footnotetext{
${ }^{8}$ Algunos lo han denominado "Estado Providencia", tomando el concepto "providencia" de la teología cristiana, pero no nos gusta este término, ya que en la teología cristiana la Providencia no sólo supone pasividad del sujeto con respecto a Dios, sino también responsabilidad activa.
} 


\subsection{El origen del cuestionamiento de la Economía Social de Mercado}

En los años 50 empezaron las desviaciones del modelo, y fue por una razón paradóiica: cuanto mejor funcionaba la Economía Social de Mercado, menos estrictamente se mantuvo la fidelidad a los principios del modelo, solía recordar Tietmeyer. Empezó una lenta deriva del Estado del Bienestar al Estado paternalista. Como recuerda el profesor Eugenio Recio, "en aquellos años 50 se fomentó la fe en la efectividad de la intervención estatal en el proceso económico: el Estado Social se extendió progresivamente, de manera que si un sector dejaba de ser competitivo en el mercado internacional, las cajas del Estado debían asegurar los puestos de trabajo y garantizar apoyo en todas las áreas: seguro de enfermedad, pensiones, mercado de trabajo". Por ello, la INSM ha propugnado un retorno al liberalismo de la Economía Social de Mercado, iniciativa que algunos han denominado "neoliberalismo", pero, tal como ya hemos indicado, en el sentido del "ordoliberalismo" de la Escuela de Friburgo de los años 30 y de la conferencia de París de 1938, que dista mucho del neoliberalismo de la Escuela de Chicago. Las raíces históricas anglosajonas no valen para Alemania ni para los países europeos que han seguido el modelo económico social de este país: la tradición cultural alemana se opondría a cualquier intento de eliminar su sistema solidario o de reducirlo a su mínima expresión. No se trata de volver al capitalismo manchesteriano, sino de estimular el ejercicio de la propia responsabilidad y de la iniciativa privada. Tietmeyer, en diferentes intervenciones, ha defendido un regreso a los principios fundamentales de la Economía Social de Mercado, despojando a este sistema de las corruptelas que ha acumulado en su desarrollo histórico. En este ordoliberalismo alemán no se pretende eliminar lo social, sino conservarlo, reformando los sistemas de protección para que puedan funcionar de forma sostenible. Aludiendo al título del conocido libro de Ludwig Erhard, Bienestar para todos, ${ }^{9}$ Tietmeyer interpreta su significado en las circunstancias actuales con estas palabras: Hoy no se trata de prometer el bienestar a cada ciudadano, más bien lo que se pretende hoy es que todos tengan una oportunidad. 'Oportunidad para todos' es el leitmotiv de los nuevos tiempos. ${ }^{10}$

Por supuesto, las críticas que la Economía Social de Mercado ha recibido desde el neoliberalismo anglosajón, especialmente de Milton Friedman y demás profesores de la Escuela de Chicago, han sido abundantes. Éstos propugnan que el Estado

\footnotetext{
9 L. ERHARD (1957) Bienestar para todos, Valencia, Fundación Ignacio Villalonga. Primera edición en alemán: L. ERHARD (1957) Wohlstand für alle, Düsseldorf, Econ-Verlag.

10 H. TietmeYer (2001) "German Reborn: The Time Has Come to Renew Germany's Social Market Economic Model", Wall Street Journal Europe, 12 de abril, 22.
} 
se retire de la economía, lo que supone una disminución enorme de los impuestos. Están convencidos, con la ingenuidad propia de los liberales del XVIII, que el mercado, por sí solo, traerá bienestar para todo el mundo. Por lo visto, dos siglos de historia no han sido suficientes para aprender la lección. Como es sabido, y no lo analizaremos aquí, en los años 80, los gobiernos de Margaret Thatcher (Gran Bretaña) y de Ronald Reagan (Estados Unidos) siguieron esta política económica neoliberal anglosajona, que posteriormente, en los 90, se acentuó con la caída del muro de Berlín y con la implosión de la Unión Soviética. No obstante, estos dos países (Estados Unidos y Gran Bretaña), y otros que les siguen, han moderado sus posturas con el cambio de siglo, y ya no ven mal una presencia importante del Estado en la economía para garantizar ciertos derechos sociales y para proteger la estabilidad de los mercados.

Frente a las críticas de los neoliberales anglosajones, la INSM recuerda que la Economía Social de Mercado no propugna el Estado paternalista y sí defiende la libertad del mercado, pero dentro de un orden, de un marco. Estos son los puntos que defiende la INSM:

- competencia en un mercado libre, así como libre formación de los precios, para estimular la iniciativa privada, la responsabilidad propia y la disposición al rendimiento;

- propiedad privada de los medios de producción, que favorece el desarrollo del espíritu empresarial;

- políticas de coyuntura y de crecimiento económico para evitar que las fluctuaciones económicas dañen a los más débiles;

- en concreto, disponer de recursos para asegurar el pleno empleo;

- políticas de estabilidad monetaria con la independencia del Banco Central, para controlar las tendencias inflacionistas;

- libertad para el comercio exterior;

- Seguridad Social, justicia social y progreso social con medidas estatales redistributivas en forma de cotizaciones sociales. El equilibrio social debe basarse en la responsabilidad ética de cada ciudadano en relación con los demás;

- la Economía Social de Mercado es un sistema abierto, no cerrado. Modifica la intensidad en la aplicación de sus principios fundamentales (ya sea esco- 
rando hacia la intervención del Estado, ya sea haciéndolo hacia la libertad de mercado), en función de las circunstancias históricas. Esta flexibilidad le faltó al liberalismo anterior a 1929 y al socialismo anterior a 1989. Ahora bien, en esta flexibilidad hay que recordar que ningún fin justifica ciertos medios. Esta apertura conlleva el riesgo de posibles graves desviaciones, sobre todo en el área de la política social.

\section{La contribución del pensamiento social cristiano}

La Doctrina Social de la Iglesia, y en general el pensamiento social cristiano, ${ }^{11}$ tuvo un importante papel en el origen de la teoría acerca de la Economía Social de Mercado, concretamente con las aportaciones de los jesuitas Oswald von NellBreuning y Gustar Gundlach y la del dominico Arthur Fridolin Utz. Para entender esta aportación histórica debemos remontarnos al siglo XIX. A finales de aquel siglo, dos sistemas económicos se estaban consolidando, uno completamente, el capitalismo, concretamente el capitalismo industrial, y el otro sólo como corriente de pensamiento, que aglutinaba ya a importantes movimientos sociales y a partidos de izquierda, el socialismo, concretamente el socialismo marxista. El Papa León XIII vio que ambos sistemas estaban adquiriendo tal envergadura, tal nivel de confrontación dialéctica, y estaban afectando de tal manera a la vida de millones de personas que, en tanto que Pastor de la Iglesia Católica, se sintió moralmente obligado a escribir acerca de estos dos sistemas. Lo hizo en la famosa encíclica Rerum Novarum (RN), publicada en 1891, expresión que significa "Acerca de las cosas nuevas", y esas cosas nuevas son el capitalismo industrial y el socialismo. El texto de León XIII es crítico con ambos sistemas, mostrando que las filosofías de uno y otro, así como alguno de sus pilares técnicos, son difícilmente conciliables con la fe cristiana. León XIII no se propuso presentar un sistema económico alternativo, ya que no le competía a él hacer tal cosa. No obstante, su encíclica, fundadora de la denominada Doctrina Social de la Iglesia, que ha aportado buen

\footnotetext{
11 Por "Doctrina Social de la Iglesia" entendemos el conjunto de documentos eclesiásticos, publicados por Papas, conferencias episcopales o por el Concilio Vaticano II, desde 1891 (año de la Rerum Novarum de León XIII) hasta hoy, que han abordado temáticas sociales, políticas y económicas desde la perspectiva cristiana católica. Por "pensamiento social cristiano" entendemos, en general, esa aportación a estas temáticas desde la perspectiva cristiana, pero no sólo la realizada en documentos eclesiásticos, sino también la producida por intelectuales cristianos (teólogos, economistas, sociólogos, filósofos, politólogos, etc.). Además, la Doctrina Social de la Iglesia hace referencia sólo al campo católico (por ello se llama "de la Iglesia", y no "de las Iglesias"), mientras que el pensamiento social cristiano incluye a cristianos de todas las confesiones.
} 
número de encíclicas a lo largo de siglo XX acerca de la economía, la sociedad y la política, puso, quizás sin pretenderlo, las bases para el sistema económico que acabaría siendo el gran descubrimiento del siglo XX en este terreno: la Economía Social de Mercado.

Cuarenta años después de esta encíclica, el Papa Pío XI quiso conmemorar ese aniversario con otra encíclica social, la Quadragesimo Anno (QA), publicada en 1931, en cuya redacción tuvo un papel protagonista Oswald von Nell-Breuning, jesuita. Si la RN había sido escrita en plena expansión de la revolución industrial, en pleno triunfo del capitalismo, por lo que ya se veían algunas de sus consecuencias más perversas, y también en plena expansión teórica, que no práctica, del socialismo, por su parte, la QA fue escrita en plena crisis del capitalismo, como consecuencia del "crack" bursátil de 1929, y en plena expansión del socialismo soviético ruso, con su primer plan quinquenal en funcionamiento (1928-32), con un desarrollo, agrícola primero, e industrial después, impresionante. Aquí ya se veían las consecuencias negativas de uno y otro sistema: a las ya divisadas en el capitalismo a finales del XIX, se sumaban ahora las consecuencias por la locura que puede llegar a constituir el capitalismo financiero sin control estatal alguno; $y$, en cuanto al socialismo se refiere, a las objeciones teóricas apuntadas ya a finales del XIX, se sumaba ahora la constatación de la pérdida de libertad individual que comportaba el socialismo. Y sin libertad individual, no hay vida humana en plenitud. Ambos fenómenos, crisis del capitalismo y ascenso del socialismo, estaban poniendo los fundamentos de los fascismos europeos, concretamente del terrible nacionalsocialismo alemán.

Evidentemente, hay otros documentos de la Doctrina Social de la Iglesia donde podemos encontrar influencias del pensamiento social cristiano en la Economía Social de Mercado, que no surgió de golpe, sino paulatinamente, como por ejemplo la encíclica de Juan XXIII, Mater et Magistra (1961), o la constitución pastoral del Concilio Vaticano II, Gaudium et Spes (1965). No obstante, preferimos centrarnos en RN y QA, dos documentos significativos por ser uno el escrito fundante de la Doctrina Social de la Iglesia, y el otro, el precedente inmediato de la Economía Social de Mercado en su versión alemana. En ellos se hace patente la aportación del pensamiento social cristiano a este nuevo sistema económico. 


\section{I. Ante el Socialismo}

Puede parecer curioso que el análisis crítico de un Papa, en este caso, León XIII, no se despertara con el capitalismo, que ya tenía siglos de existencia, ni siquiera con el capitalismo industrial, que ya tenía cien años, sino con el socialismo. ¿ᄅPor qué el auge del capitalismo industrial, a finales del siglo XVIII, no despertó la cólera pontificia, y sí en cambio la proximidad del socialismo? No obstante, para ser más precisos, debemos decir que el Papa León XIII critica, no exactamente en estos términos, la situación de pobreza de la clase obrera como consecuencia de la revolución industrial (lo cual ocurre en el siglo XIX avanzado, no antes), y critica igualmente el socialismo como alternativa. El documento del Papa salió en 1891, cuando ya era patente la situación de pobreza del proletariado. Difícilmente podría haber salido, por ejemplo, un siglo antes. Ahora bien, cuando se despertó la crítica católica oficial, mordió a uno y a otro sistema. Primero al socialismo. León XIII, en la $\mathrm{RN}$, critica el socialismo por la pretensión que esta corriente de pensamiento tiene de suprimir la propiedad privada. ${ }^{12}$ Frente a esto, la RN defiende que la propiedad, y en particular la propiedad privada, es un derecho natural. ${ }^{13}$ Ahora bien, como bien explica el profesor Ildefonso Camacho, no se trata de un derecho natural primario (de los que emanan directamente de la naturaleza humana), sino secundario (al que se llega a través de un proceso de la razón). ${ }^{14}$ La propiedad es un derecho natural no de carácter absoluto, sino en relación con un deber social. La propiedad tiene una función social, idea que aparece sólo apuntada en este texto, ${ }^{15}$ y ampliamente desarrollada en otros posteriores, e incluso en documentos de siglos anteriores, acuñada con la expresión "destino universal de los bienes", tal como veremos más adelante.

También critica al socialismo su apuesta por la revolución violenta como medio para lograr un radical cambio de estructuras económicas (RN, 2).

\footnotetext{
${ }^{12}$ El texto dice: los socialistas empeoran la situación de los obreros todos, en cuanto tratan de transferir los bienes de los particulares a la comunidad, puesto que, privándolos de la libertad de colocar sus beneficios, con ello mismo los despojan de la esperanza y de la facultad de aumentar los bienes familiares y de procurarse utilidades (RN, 3). Y más adelante, califica de "fantasía" la pretensión socialista de reducir la propiedad privada a propiedad común (RN, 11).
}

${ }^{13}$ El Papa escribe: el poseer algo en privado como propio es un derecho dado al hombre por la naturaleza (RN, 4). Estamos, dice, ante un principio "inviolable" (RN, 11 ; 33).

${ }^{14}$ I. CAMACHO (1991) Doctrina Social de la Iglesia. Un aproximación histórica, Madrid, San Pablo, 74.

${ }^{15}$ El texto dice: a pesar de que [la propiedad] se halle repartida entre los particulares, no deja por ello de servir a la común utilidad de todos... (RN, 6). 
Cuarenta años después, el Papa Pío XI volvió sobre estos temas, en un contexto histórico, como hemos dicho, radicalmente distinto al de 1891. El Papa sigue viendo errores importantes en el capitalismo, como indicaremos enseguida, pero no cree que el socialismo soviético, ni siquiera el socialismo moderado de algunos partidos de la Europa Occidental, sea una solución adecuada. El Papa defiende que tanto el capital como el trabajo son necesarios para la actividad económica: de nada sirve que uno se imponga sobre el otro; deben vivir en armonía. El Papa propuso incluso el sistema corporativista, de asociaciones libres de patronos y obreros, no controladas por el Estado. No obstante, esta propuesta tuvo la mala fortuna de parecerse demasiado a la de los fascistas italianos, que defendían corporaciones semejantes, pero controladas por el Estado, con la intención de ahogar la democracia. Como explica el profesor Ildefonso Camacho, la sociedad de la época no entendió la diferencia entre el modelo propuesto por la Quadragesimo Anno (corporaciones de iniciativa privada no sometidas al Estado) y el fascista (corporaciones creadas y controladas por el Estado que sirven para encuadrar a toda la sociedad y mantenerla sometida al poder político) (QA, 91-95). Por eso el proyecto sugerido por Pío XI quedó definitivamente descalificado tras la derrota del fascismo italiano y el nazismo, sin que el experimento franquista en España o salazarista en Portugal añadieran nada digno de tenerse en cuenta para resolver los conflictos típicos de una sociedad industrial avanzada. ${ }^{16}$

Frente a los radicales y violentos cambios que promueve el socialismo, el Papa Pío XI apuesta por una reforma de las instituciones (el ya mencionado corporativismo) y por una reforma de las costumbres, que comentaremos más adelante. Armonía entre clases, en lugar de lucha de clases. Ésta fue su apuesta, difícil de ser sostenida en los convulsos años 30. La crítica al comunismo continuó con la encíclica Divini Redemptoris, del 19 de marzo de 1937, sólo cinco días después de la publicación de la famosa Mit brennender Sorge (14 de marzo de 1937), dura crítica al Nazismo.

\subsection{Ante el Capitalismo}

Aunque la RN fue una crítica directa al socialismo, ello no le llevó al Papa León XIII a defender el capitalismo, ni tampoco su correspondiente filosofía social, el liberalismo. Al contrario, las críticas se repartieron entre ambos sistemas. Al capitalismo, la RN le critica su absolutización de la propiedad privada, que ha tenido

\footnotetext{
${ }^{16}$ I. CAMACHO (1995) Creyentes en la vida pública. Iniciación a la doctrina social de la Iglesia, Madrid, San Pablo, 57.
} 
como nefasta consecuencia unas desigualdades sociales injustas (RN, 1). Para la doctrina católica, la propiedad es un derecho natural, sí, pero tiene una función social. El propietario no sólo puede disfrutar de su propiedad, sino que también debe preguntarse cómo puede beneficiarse la sociedad de ésta su propiedad: está moralmente obligado a hacerlo $(\mathrm{RN}, 16) .{ }^{17} \mathrm{El}$ hombre, más que propietario de bienes, es su administrador. León XIII defiende la intervención del Estado para garantizar el acceso de todos a la propiedad (RN, 33), pero sólo con dos objetivos: 1 / la defensa de la propiedad (RN, 28), y 2 / la defensa de los desfavorecidos, de los que carecen de propiedad (RN, 27). En concreto, el Papa no cree que el trabajo deba quedar sometido a los vaivenes del mercado: el Estado tiene que intervenir para imponer salarios justos (RN, 32). No acaban aquí las críticas de León XIII al liberalismo. El Papa, frente a los capitalistas, defiende el derecho a la libre asociación, aunque prefiera las corporaciones interclasistas (empresarios y obreros unidos) a los sindicatos horizontales (obreros unidos frente a la patronal).

Cuarenta años después, en 1931, en la QA, Pío XI es aún más duro en su crítica del capitalismo de lo que lo había sido León XIII. Llega a calificarlo de dictadura económica (QA, 105) por su lógica tendencia a los monopolios, que hacen imposible el libre mercado. Pío XI considera que el capitalismo ha introducido en la vida humana costumbres insanas, como la insaciable sed de riquezas y de bienes temporales (QA, 132), que constituyen la perversión de todo el sistema económico. Por ello, propone una reforma de las costumbres; concretamente apuesta por la moderación y por la caridad. Con la moderación se logra un adecuado equilibrio entre fines y medios; con la caridad, se ponen los fundamentos para evitar las desigualdades sociales $y$, con ello, la lucha de clases. ${ }^{18}$

\subsection{En los fundamentos de la Economía Social de Mercado}

Como hemos dicho más arriba, la Economía Social de Mercado tiene dos pilares, y ambos están tomados del humanismo cristiano: la libertad individual y la sensibilidad social. El primero de ellos, la libertad individual, se afirma contra la pretensión socialista de diluir al individuo en un Estado omnipresente en economía. Ningún Estado tiene derecho a suprimir las libertades individuales. Este pilar lleva consigo el principio de subsidiariedad. El segundo pilar, la sensibilidad social,

17 Cfr. J. Sols (2002) "La propiedad: ¿derecho o blasfemia?", Iglesia Viva. Revista de Pensamiento Cristiano n ${ }^{\circ} 211,47-64$.

${ }^{18}$ I. CAMACHO. (1995) op. cit., 58. 
que también podremos denominar "solidaridad comunitaria", se afirma frente al capitalismo, un sistema que prescindía de la preocupación por los desfavorecidos, arguyendo que la "mano invisible" acabaría dando riqueza a todos. No cabe duda de que los logros económicos y tecnológicos de la "mano invisible" liberal han sido extraordinarios a lo largo de los siglos XIX y XX, pero no es menos cierto que el mercado no ha cubierto todas las necesidades humanas: ha satisfecho necesidades secundarias y terciarias de minorías adineradas antes que las necesidades primarias de mayorías empobrecidas. En el mercado, la oferta no se ha dirigido a la demanda con necesidad, sino a la demanda con dinero. A veces, el dinero y la necesidad coinciden, pero no siempre. Este segundo pilar conlleva el principio de solidaridad.

\section{a) El principio de subsidiariedad}

En la Antigüedad, el subsidium era un método de organización militar: una línea de tropa permanecía en alerta, por detrás del frente de batalla, dispuesta a dar auxilio en caso de debilidad. Con el tiempo, este método se convirtió en un principio que se extendió al orden filosófico, jurídico, social y político. Sus raíces son muy antiguas, incluso aunque el término subsidiariedad sea más reciente.

El principio de subsidiariedad viene de la Grecia antigua, recorre toda la escolástica medieval, es retomado en la Doctrina Social de la Iglesia, concretamente en la RN, y curiosamente ha servido para construir la Unión Europea a partir del tratado de Maastricht. Según este principio, la toma de decisiones ha de estar lo más cerca posible del individuo. Sólo cuando éste no pueda tomarlas por sí solo, el nivel social de decisiones irá ascendiendo, quizás hasta llegar al Estado. Lo interesante de este principio es que sitúa el poder, la responsabilidad, en el individuo, en la persona, en la base de la sociedad. La construcción política está al servicio de esta persona, en realidad, de todas la personas, pero nunca podrá sustituir su libertad.

El pensamiento social cristiano afirma, contra el capitalismo, que el Estado debe asumir aquello socialmente importante que los particulares no llegan a afrontar (podría ser el caso de los transportes, la sanidad, la educación), y contra el socialismo, que el Estado no debe asumir aquello que los particulares pueden afrontar por su cuenta (iniciativa para los negocios, mercado, formación cultural, ideológica, moral, religiosa). 


\section{b) El principio de solidaridad}

El principio de solidaridad, aunque no menos importante, es mucho más sencillo de entender que el de subsidiariedad. Este principio afirma que todos los seres humanos somos, de alguna manera, hermanos. La solidaridad es la versión moderna de la fraternidad, principio cristiano ${ }^{19}$ recogido por los revolucionarios franceses ${ }^{20}$ aunque curiosamente la supuesta fraternidad revolucionaria francesa llenó de cabezas cortadas la plaza de la guillotina. Esta solidaridad hace que unos debamos preocuparnos por los otros, especialmente por los más desfavorecidos. El pensamiento social cristiano afirma que un buen sistema económico será aquel que no genere víctimas, y en caso de que no logre evitarlo, que cree sistemas estructurales de atención especial hacia esas víctimas para que dejen de serlo. Aquí se puede hacer necesaria la intervención del Estado, frente al capitalismo, que consideraba insoportable esta intervención. El Estado debe garantizar que no haya pobres, que no haya marginados, que haya trabajo para todos, si el libre mercado no lo consigue. Ahora bien, frente al socialismo se afirma que la solidaridad no debe atentar contra la subsidiariedad, sino articularse con ella. Por el supuesto principio de solidaridad, el Estado (socialista) no tiene derecho a atribuirse todo tipo de competencias, sino sólo aquellas necesarias de manera subsidiaria.

\subsection{Tres principios éticos cristianos en economía}

Si los principios de subsidiariedad y de solidaridad son las dos grandes aportaciones del pensamiento social cristiano a la economía, concretamente entre los siglos XIX y XX, la Iglesia fue afinando más en sus formulaciones, especialmente a partir del Concilio Vaticano II, de manera que los principios éticos quedaron fijados en estos tres: el destino universal de los bienes, el desarrollo integral y solidario, y la opción preferencial por los pobres. ${ }^{21}$

\footnotetext{
19 Siguiendo la lógica evangélica, si Dios es Padre de todos, entonces todos somos hermanos.

20 El lema revolucionario fue: "libertad, igualdad y fraternidad".

${ }^{21}$ Cfr. Departamento de Pensamiento Social Cristiano (2000) Una nueva voz para nuestra época (PP 47), Madrid, Universidad Pontificia Comillas, 225-228. En esta obra se habla de "amor preferencial por los pobres", pero preferimos utilizar aquí la expresión "opción preferencial por los pobres", por ser más habitual en el pensamiento social cristiano.
} 
a) El destino universal de los bienes. El destino universal de los bienes contiene la tesis de que todos los bienes están destinados a todos los hombres. ${ }^{22}$ Esto conlleva dos cosas: la afirmación de la propiedad como derecho natural, y la función social de la propiedad. Tal como escribía uno de los autores este estudio en su artículo "La propiedad: ¿̇derecho o blasfemia?", según el primer punto, la propiedad no es simplemente una costumbre social fáctica, sino un derecho, más aún, un derecho natural, o sea, anterior a las legislaciones que sobre el tema puedan hacer los Estados, un derecho vinculado al ser humano mismo. Esto significa, por ejemplo, que todos los bebés que nacen sin propiedades tienen derecho, por naturaleza, a ellas, se entiende, las necesarias para vivir. Y si crecen sin tenerlas, entonces la humanidad atenta contra un derecho natural y comete un pecado contra el plan de Dios. ${ }^{23}$ Según el segundo punto (la función social de la propiedad), no sólo el propietario se puede beneficiar de sus posesiones, sino el conjunto de la sociedad a la que pertenece el propietario. Si alguien se enriquece, no sólo él debe gozar de esa riqueza, sino la sociedad en la que él vive. ${ }^{24}$

Como hemos visto, RN defendía la propiedad privada, pero no le daba el carácter absoluto que ella tenía en el capitalismo. La función social de la propiedad supedita ésta al destino universal de los bienes. Todo ser humano tiene derecho a disfrutar de los bienes de la tierra. La economía deberá organizar un sistema que garantice este derecho, no que lo suprima.

b) El desarrollo integral y solidario. El desarrollo integral y solidario apunta a dos horizontes: el del respeto a la totalidad del ser humano (integridad de lo humano) y el del respeto a la totalidad de los seres humanos (solidaridad con los pueblos desfavorecidos). La economía debe cuidar todo el hombre (integridad) y a todos los hombres (solidaridad). En el primer horizonte, el ser humano no puede ser reducido a la categoría de simple pieza de un engranaje empresarial. En el segundo, ningún ser humano puede ser apartado del sistema de producción y distribución de bienes y servicios.

c) La opción preferencial por los pobres. La opción preferencial por los pobres enlaza con el desarrollo solidario. Si un sistema económico, ya sea nacional, ya

\footnotetext{
22 Ibíd., 226.
}

${ }^{23}$ Aunque ya hemos señalado más arriba que se trata de un derecho natural secundario, no primario.

24 J. Sols (2002) op. cit., 48. 
sea global, genera pobreza, el cristianismo pone como imperativo moral el trabajo prioritario para paliar esa pobreza.

Así, sin haberlo pretendido verdaderamente, el pensamiento social cristiano puso las bases para un sistema económico considerablemente humano, denominado "Economía Social de Mercado". Como dijo Josep Antoni Duran Lleida en su conferencia, la Economía Social de Mercado no es simplemente un punto intermedio entre capitalismo y socialismo, sino mucho más. No se trata de entender este sistema como una variación del capitalismo a la que se le ha colocado la etiqueta de 'social'. No es esto. La Economía Social de Mercado se caracteriza por una visión propia del hombre, de la persona humana y de la comunidad, para situar la economía al servicio de la persona y de la comunidad. Sin esta inspiración ideológica, creo que no hay Economía Social de Mercado, sino un sistema capitalista más o menos reformado. Por eso, la implantación de una Economía Social de Mercado sólo será posible si entendemos la economía como un instrumento poderoso, pero no como una realidad despótica que no se puede cambiar y que condiciona todas nuestras acciones. La Economía Social de Mercado no es un híbrido de dos sistemas, sino un sistema coherente, original, que ya ha funcionado durante medio siglo, con excelentes resultados, y que se encuentra ahora en un difícil proceso de adaptación a la globalización, debido a que no hay ningún Estado global que pueda regular la economía global. Sin Estado, no hay Economía Social de Mercado.

Podemos afirmar sin rubor que la Economía Social de Mercado es una criatura, al menos parcialmente, cristiana, que nació en la Alemania de posguerra, en buena medida a la sombra del pensamiento de los socialcristianos, esto es, de la democracia cristiana, y tuvo entre sus padres a pensadores cristianos. Junto a esto, obviamente, hay que decir también que los socialdemócratas (la corriente democrática dentro del socialismo) pronto apoyaron este sistema económico, al ver en él una neta superación de los males del denominado "socialismo real".

\section{Reformas necesarias en el nuevo contexto de la globalización}

La Economía Social de Mercado ha ido de la mano del Estado del Bienestar. Son las dos caras de una misma moneda llamada "modelo social europeo". La cara económica de este modelo ha sido la Economía Social de Mercado; su cara política, el Estado del Bienestar. En su conferencia, el Consejero ("Conseller") de Economía y Finanzas de la Generalitat de Catalunya, Antoni Castells, afirmó con 
rotundidad que debemos estar orgullosos del Estado del Bienestar y del conjunto de este modelo social, que nació en Europa, concretamente en Alemania, tras la II Guerra Mundial, con el importante precedente del New Deal norteamericano del economista Keynes y del presidente Roosevelt. Este modelo social, fruto de un pacto histórico entre los dos grandes agentes económicos y sociales de la época, empresarios y trabajadores, logra un equilibrio entre sector público y mercado, entre crecimiento económico y redistribución de la renta, entre los incentivos al esfuerzo individual y la protección social, y entre la competitividad y la solidaridad. En ningún lugar del mundo como en Europa se ha dado un equilibrio tan adecuado entre espacio público y libertad individual. Ante la tradicional oposición espacio público / libertad individual, decía Castells, hay que afirmar que el espacio público es el lugar donde se ejerce la libertad individual. Éste es el genio de Europa. Éste es el modelo social europeo.

\section{I. Fundamentos del Estado del Bienestar}

El Estado del Bienestar fue el marco político que hizo posible el desarrollo de la Economía Social de Mercado, y al mismo tiempo fue el resultado de ésta. En sus fundamentos tenemos: 1/ un sector público implicado activamente en la prestación de servicios públicos, en particular, educación, salud y pensiones; 2 / una implicación del sector público en la orientación global de la economía (resultado de las teorías de Keynes); se afirma que tiene que haber políticas macroeconómicas, y 3 / un pacto social, esto es, un compromiso común de los principales agentes sociales (que en los años 40 fueron los empresarios y los trabajadores), a fin de ponerse de acuerdo en las reglas de juego.

\subsection{Causas del cambio de contexto histórico}

En este medio siglo que nos separa del inicio de la Economía Social de Mercado, el contexto histórico ha cambiado notablemente. Especialmente en estas dos últimas décadas se han dado importantes cambios que hacen necesaria una reforma a fondo del Estado del Bienestar, pero no su desmantelamiento. Veamos cuáles son los cambios principales.

1. La globalización ha abierto definitivamente el mercado y ha roto las fronteras nacionales. El ámbito donde se lleva a cabo la competencia económica ya no es la región ni la nación, sino el mundo. El Estado del Bienestar nació en el contexto de economías nacionales. Ese modelo ya no sirve. Se ha roto la 
baraja. Hay que repensar la relación política-economía, hay que repensar las reglas del juego, hay que reformular de arriba a abajo el sistema fiscal.

2. Los cambios sociodemográficos. La sociedad europea ha cambiado enormemente en estos sesenta años de Economía Social de Mercado. Entonces había una abundante población juvenil, de cuyo trabajo salían las pensiones para mantener a la no tan numerosa población anciana. En cambio, hoy en día escasean los jóvenes y abundan los ancianos. La sociedad se ha envejecido. Resulta difícil que el trabajo de los jóvenes y de los adultos en edad activa costee las pensiones de la engrosada tercera edad, que va de los 65 a los más de 90 años. Además, hace medio siglo había básicamente un solo modelo familiar, mientras que ahora los modelos familiares, o como se les quiera llamar, son de lo más variopinto.

3. Han cambiado las necesidades sociales, por lo que se hace necesario cambiar también el pacto social. Ya hemos dicho que los actores sociales de los años 40 eran los empresarios y los trabajadores, en el contexto de una sociedad muy industrializada. Hoy hay nuevos actores, en una sociedad menos industrializada, y los viejos actores se han vuelto conservadores, reacios a establecer un nuevo pacto social en el que ellos no tengan un papel central. Tan conservadores son para ello los empresarios como los trabajadores.

4. El fenómeno migratorio. Resulta obvio que la llegada abundante de inmigrantes extracomunitarios a Europa ha cambiado la fisonomía de nuestra sociedad, que es mucho más heterogénea que antes. Ya no estamos simplemente en una sociedad de ciudadanos europeos, sino que ahora tenemos también: $1 /$ habitantes "sin papeles", 2/ habitantes con permiso de residencia temporal, y 3/ ciudadanos de origen extranjero con características culturales muy distintas, por ejemplo, en relación a la educación básica obligatoria o a la condición de la mujer.

5. Se ha dado un importante cambio de valores. En los años 40 , decía Antoni Castells, había un cierto consenso de valores en torno a las ideas de igualdad y de progreso. Hoy, en cambio, prima el valor de la libertad individual y el valor de la sostenibilidad (que incluye la idea de que el progreso no sea sólo para nosotros, sino también para las generaciones futuras). La igualdad y la solidaridad van a la baja.

6. No cabe duda de que también hay causas endógenas del cambio que se ha dado en nuestro modelo social. Según Castells, el sector público ha generado 
dinámicas negativas, lo que ha llevado, por ejemplo, al hecho de que Estados Unidos tenga un PIB per cápita con paridad de poder de compra superior al de cualquier país europeo. Si el de Estados Unidos fuera de 100, el de Dinamarca sería de 80, el de Gran Bretaña y el de Holanda, de 78, y el de Francia de 76. Esto no es necesariamente debido a una menor productividad, ya que la americana y la europea son similares (la francesa es incluso ostensiblemente superior a la americana), sino sobre todo es debido a que en Estados Unidos, en relación a su población activa, hay más personas que trabajan, y además trabajan más horas. Algunos, como Olivier Blanchard, economista del MIT, interpretan esta diferencia como una mayor cultura del ocio en Europa que en Estados Unidos, donde habría una mayor cultura del trabajo, mientras que otros lo atribuyen a factores institucionales, como una mayor rigidez del mercado de trabajo y una más exigente fiscalidad en Europa que en Estados Unidos. La mayor rigidez en el mercado de trabajo dificultaría la contratación, y la más exigente fiscalidad desanimaría a mucha gente, que optaría por no trabajar tanto como se trabaja en Estados Unidos. En Estados Unidos, en cambio, donde el Estado del Bienestar protege al ciudadano mucho menos que en Europa, la gente tiene que trabajar mucho para autoprotegerse y para asegurarse el futuro: seguros médicos, seguros de vida, pensión de jubilación, universidad para los hijos, etc.

Los países nórdicos han demostrado durante décadas que el mejor Estado del Bienestar puede generar un crecimiento económico extraordinario de la mano de la justicia social.

\subsection{Líneas de reforma del Estado del bienestar para mantener el modelo social}

Según Antoni Castells, las líneas fundamentales de reforma del Estado del Bienestar deberían ser:

1. Invertir aún más en políticas sociales (familia, educación...), ya que son, a la larga, una enorme inversión productiva.

2. Lograr servicios públicos de calidad, y que garanticen la igualdad de oportunidades. Hasta ahora se ha insistido mucho en la universalización de los servicios públicos, pero la calidad ha dejado mucho que desear.

3. Conviene limitar notablemente las subvenciones, ya que tienden a rebajar el 
nivel de exigencia. Sin duda, las subvenciones son necesarias, más aún, son la expresión institucional de la solidaridad, pero también son peligrosas, por lo que hay que acotarlas de manera razonable.

4. Debemos lograr un mercado de trabajo mucho más flexible, como el de los países nórdicos. La regla de oro es, afirmaba Castells, un trabajo para cada ciudadano, pero no siempre el mismo trabajo. Esta flexibilidad supone capacidad de adaptación del ciudadano a nuevos puestos de trabajo, y ello supone una mayor formación. Hay que acabar con la idea del me formé para hacer esto, y me jubilaré haciéndolo.

5. Hay que sobredimensionar el Estado del Bienestar, que hasta ahora ha sido nacional. Tiene que pasar a ser europeo. Según Antoni Castells, la realidad económica es europea, incluso global, pero un Estado del Bienestar mundial no es todavía realizable. Sí lo es, en cambio, el europeo, que nos daría la cintura que demuestran las economías americana y china, por ejemplo.

\section{Conclusión}

Afirmar que la Economía Social de Mercado es uno de los grandes logros de la historia de la humanidad no es en absoluto exagerado. Con ella se han alcanzado cotas de calidad de vida antes nunca vistas; con ella ha disminuido enormemente la distancia entre ricos y pobres en el seno de una misma sociedad, tarea nada fácil. Este sistema tuvo un doble nacimiento: en Estados Unidos, con el New Deal, en plena recesión económica como consecuencia del "crack" bursátil de 1929; y en Europa, concretamente en Alemania, después de la profunda crisis producida por la II Guerra Mundial. Hubo treinta dulces años, de los 40 a la crisis del petróleo de 1973, en los que el crecimiento económico fue extraordinario, y los logros sociales, inimaginables un siglo atrás. Todo ello se hizo de la mano del denominado Estado del Bienestar.

Además, la Economía Social de Mercado apareció en un momento en el que dos grandes sistemas económicos tenían un poderío formidable: el capitalismo, con su ideología liberal del "laissez faire, laissez passer" y su fobia a la intervención del Estado en economía, y el socialismo, que con su rígida planificación central estaba dando como resultado un crecimiento económico extraordinario en la Unión Soviética. Por el camino, el capitalismo dejaba un reguero de pobreza en lo que durante años se ha denominado Tercer Mundo, y el socialismo, un re- 
guero de derechos humanos masacrados al este del Telón de Acero. Uno ofrecía crecimiento a costa de la igualdad; el otro, igualdad a costa de la libertad. Dos costes excesivos. La Economía Social de Mercado mostró que ambos eran malos sistemas, dado que generaban formas de inhumanidad de manera estructural, y mostró también que la libertad del mercado puede ir de la mano de un Estado protector pero no opresor.

El pensamiento social cristiano, con su doble defensa de la libertad y de la solidaridad, fue decisivo en el diseño de este sistema. Curiosamente, aunque ningún Papa se había propuesto tal cosa, los documentos de la Doctrina Social de la Iglesia pusieron las bases para el desarrollo de la Economía Social de Mercado, prueba de lo cual es que entre los padres de este sistema económico había cristianos, especialmente católicos, y algunos incluso religiosos con formación teológica, como jesuitas y dominicos. Esto muestra que la reflexión antropológica interior a la teología puede aportar cosas muy interesantes a las ciencias sociales: ya había ocurrido en el siglo XVI con la Escuela de Salamanca y con algunos de los misioneros españoles en América, y volvería a ocurrir en el último tercio del siglo XX en América Latina con la Teología de la Liberación.

La Economía Social de Mercado necesita la intervención del Estado en economía, ponderada por el principio de subsidiariedad. Sin este Estado moderadamente interventor, la Economía Social de Mercado no funcionaría. En el actual contexto mundial, la economía es global, mientras que las estructuras políticas siguen siendo nacionales (sólo la Unión Europea tiene una estructura supranacional). A pesar del aparente optimismo del Conseller Antoni Castells, la Economía Social de Mercado difícilmente sobrevivirá en el siglo XXI, a no ser que nos pongamos a construir una estructura política democrática mundial, acorde con la economía global. ${ }^{25}$ Si no es así, emulando un título del escritor colombiano Gabriel García Márquez, la historia de la Economía Social de Mercado será en el siglo XXI la crónica de una muerte anunciada.

\footnotetext{
${ }^{25}$ No hemos abordado este punto en nuestro estudio. Quizás sea el objeto de otro estudio en el futuro. De momento, recomendamos la siguiente propuesta de estructura política democrática global: J. Sols et al (2007) Gobernabilidad democrática global. Una propuesta institucional, Barcelona, Raima.
} 